\title{
Hair Loss After Metabolic and Bariatric Surgery: a Systematic Review and Meta-analysis
}

\author{
Wen Zhang ${ }^{1} \cdot$ Meiling Fan ${ }^{2} \cdot$ Cunchuan Wang ${ }^{3,4} \cdot$ Kamal Mahawar $^{5} \cdot$ Chetan Parmar $^{6,7} \cdot$ Weiju Chen ${ }^{1}$. \\ Wah Yang ${ }^{3,4,8,9}$ (D) on behalf of Global Bariatric Research Collaborative
}

Received: 31 January 2021 / Revised: 23 February 2021 / Accepted: 23 February 2021 / Published online: 5 March 2021

(C) The Author(s) 2021

\begin{abstract}
Background Hair loss is a common complication after metabolic and bariatric surgery (MBS). There is a lack of published systematic review in the scientific literature on this topic. The aim of this study was to perform a systematic review and metaanalysis on hair loss after MBS in accordance with Preferred Reporting Items for Systematic reviews and Meta-Analysis (PRISMA) guidelines.

Methods PubMed, CINAHL, EMBASE, Web of Science, SCOPUS, and four Chinese databases were searched. Data were pooled using Review Manager 5.3 and Stata 12.0, and subgroups were performed if necessary and feasible.

Results A total of 18 studies $(n=2538)$ were included. The pooled results showed that the incidence of hair loss after MBS was $57 \%$ (95\% CI 42-71\%). It decreased with longer follow-up times. Hair loss was significantly more common in younger (mean difference (MD), $-2.45 ; 95 \% \mathrm{CI},-4.26$ to $-0.64 ; p=0.008$ ) women (OR, 3.87; 95\% CI, 0.59 to $17.59 ; p=0.08)$. Serum zinc (standardized mean difference (SMD), $-1.13 ; 95 \% \mathrm{CI},-2.27$ to $0.01, p=0.05$ ), folic acid (SMD $=-0.88,95 \% \mathrm{CI}-1.29$ to $0.46, p<0.0001$ ), and ferritin levels (SMD, $-0.22 ; 95 \% \mathrm{CI},-0.38$ to $-0.05 ; p=0.01$ ), but not serum iron and vitamin $\mathrm{B}_{12}$, were associated with hair loss following MBS.

Conclusions Hair loss is common after MBS especially in younger women, and those with low serum levels of zinc, folic acid, and ferritin. Prospective studies on larger cohorts are needed.
\end{abstract}

Keywords Hair loss $\cdot$ Bariatric surgery $\cdot$ Metabolic surgery $\cdot$ Nutrition $\cdot$ Meta-analysis

Key Points:

1. The incidence of hair loss after MBS was significant but it decreased with longer follow-up times.

2. Hair loss was significantly more common in younger women, and patients with low serum levels of zinc, folic acid, and ferritin had a higher chance of hair loss after MBS.

3. Serum iron and vitamin $B_{12}$ were not statistically associated with hair loss after MBS.

Weiju Chen

chenweiju@qq.com

$\bowtie \quad$ Wah Yang

yangwah@qq.com; yangwah@connect.hku.hk

1 School of Nursing, Jinan University, Guangzhou, No.601, Huangpu Avenue West, Guangzhou, Guangdong, China

2 Department of Biliary Tract Surgery, West China Hospital, Sichuan University, Chengdu, Sichuan, China

3 Department of Metabolic and Bariatric Surgery, The First Affiliated Hospital, Jinan University, No. 613, Huangpu Avenue West, Guangzhou, Guangdong, China
4 Joint Institute of Metabolic Medicine between State Key Laboratory of Pharmaceutical Biotechnology, The University of Hong Kong and Jinan University, Guangzhou, China

5 Bariatric Unit, Sunderland Royal Hospital, Sunderland, UK

6 Department of Surgery, Whittington Hospital, London, UK

7 University College London Medical School, London, UK

8 State Key Laboratory of Pharmaceutical Biotechnology, LKS Faculty of Medicine, The University of Hong Kong, Hong Kong, China

9 Department of Medicine, LKS Faculty of Medicine, The University of Hong Kong, Hong Kong, China 


\section{Introduction}

The prevalence of overweight and obesity has been increasing globally and it has become a major public health concern in many countries [1]. Metabolic and bariatric surgery (MBS) is now a recognized treatment strategy for patients with severe, complex obesity meeting the accepted criteria $[2,3]$.

Hair loss is a recognized complication of MBS. Some researchers have noted hair loss in more than half of the patients in the short term after MBS [4]. Others have demonstrated that iron and zinc levels are associated with hair loss [5]. Although hair loss does not usually result in severe morbidity, it can cause unnecessary alarm and affect mental health, self-esteem, and quality of life of the patient [6].

The incidence of hair loss after MBS varies in different studies. One study reported that $15.4 \%$ of patients experienced hair loss within 3 months after RYGB [7]. A previous study by some of the authors found that the incidences were 55\% and $40 \%$ after laparoscopic sleeve gastrectomy (LSG) and laparoscopic Roux-en-Y gastric bypass (LRYGB) respectively within 6 months. It is similar to Ruiz-Tovar's report of $41 \%$ after LSG, in 2014 [5]. Others have found the incidence to be as high as $80 \%$ after laparoscopic gastric plication (LGP) or LSG [8].

There is some suggestion that the incidence decreases with time. For example, Ledoux et al. [4] reported that the incidence of hair loss after MBS decreased from $65 \%$ at $\leq 1$ year to $35 \%$ at $\geq 3$ years. Guo et al. [9] observed that the onset time and end time of hair loss were $3.4 \pm 1.4$ months and $9.03 \pm 3.6$ months, respectively. In 42 cases of hair loss, 15 patients received oral medication without significant improvement of hair loss. However, during the follow-up period (15months), hair loss stopped and new hair gradually grew out in all patients. The incidence of short-term and long-term hair loss after bariatric surgery is not consistent.

There is also considerable debate in the scientific literature regarding its etio-pathogenesis. For instance, Katsogridaki et al. [10] found that vitamin $B_{12}$ tended to be lower in patients with hair loss compared with controls. Nevertheless, the opposite conclusion was found by Ledoux et el. [4] Furthermore, Sen et al. [11] also did not find any therapeutic benefit with Biotin supplements. Role of other micronutrient deficiencies such as those of folic acid, zinc, and iron is also controversial $[4,5,9]$.

There is currently no published systematic review in the scientific literature on hair loss after MBS examining all these various issues. We, therefore, performed a systematic review and meta-analysis on this topic in accordance with Preferred Reporting Items for Systematic reviews and Meta-Analysis (PRISMA) guidelines [12].

\section{Methods}

Two authors independently and systematically performed literature searches on PubMed, CINAHL, EMBASE, Web of Science, SCOPUS, China National Knowledge Infrastructure (CNKI), the Database of Chinese Ministry of Science \& Technology (Wanfang), and the Database of Chinese Science and Technology Periodicals (VIP) from the inception of the database to July 2020, with the following search terms: "(bariatric surgery OR weight loss surgery OR obesity surgery OR metabolic surgery OR gastric bypass OR sleeve gastrectomy OR gastric banding OR duodenojejunal bypass OR duodenal switch) AND (alopecia OR hair loss)". In addition, we also manually searched the reference list of published documents.

\section{Inclusion and Exclusion Criteria}

Articles were included if they met the following criteria: (1) patients with body mass index (BMI) greater than $30 \mathrm{~kg} / \mathrm{m}^{2}$, age 18-65 years, and (2) provide the incidence of hair loss after MBS or its etiological factors.

Case reports, reviews and non-English/Chinese studies, revision surgery, and conference abstracts of unpublished data were excluded. For studies enrolled overlapping populations, we only included the study with the most comprehensive information.

\section{Data Extraction and Quality Assessment}

Two researchers (Wen Zhang and Meiling Fan) independently screened the title, abstract, and full text of the articles based on the inclusion and exclusion criteria. Any discrepancies that occurred during the full-text screening stage were resolved by consensus between the two reviewers. The characteristics of the included studies are presented in Table 1. A prespecified data extraction form was used to record the following data: the first author of the study, the year of publication, location of trial, number of subjects, sex, mean age at time of surgery, length of follow-up, mean BMI before surgery, study design, type of bariatric surgery, and outcome indicators.

To evaluate the quality of the observational studies $[4,5,9$, $10,13,15,17-20,24,25]$, we employed the nine-point Newcastle-Ottawa Scale (NOS) [26], which assesses three fundamental aspects of methodology: study participant selection ( $0-4$ points), confounder adjustment $(0-2)$, and outcome indicator determination (0-3). A study with an NOS score of 7-9 points was defined as high quality. The methodological quality of the cross-sectional studies [14, 16, 21-23] included was assessed using an 11-item checklist recommended by Agency for Healthcare Research and Quality (AHRQ) [27]. An item would be scored "0" if it was answered "NO" or "UNCLEAR"; if it was answered "YES," then the item scored 





"1." Article quality was assessed as follows: low quality $=0$ 3 ; moderate quality $=4-7$; high quality $=8-11$. The Talebpour study in 2018 was a randomized controlled trial (RCT) [8] and was assessed using the Jadad scale [28]. A study with a Jadad score of 4 or more was considered to be high quality. The quality score is presented in Table 1.

\section{Statistical Analysis}

Categorical variables are reported as frequencies and percentages, and continuous data are expressed as the mean \pm standard deviation (SD). For continuous variables, the mean difference (MD) or standardized mean difference (SMD) with the $95 \%$ confidence interval $(\mathrm{CI})$ was used when appropriate, depending on whether or not the outcomes were measured by the same scales, while the odds ratio (OR) with $95 \%$ CI was used for dichotomous variables (hair loss frequency). All statistical analyses were performed on Review Manager (RevMan version 5.3) and Stata (version 12.0), with the significance level set to $p<0.1$. Heterogeneity was measured using the I-square statistic, with a significance threshold of $\mathrm{I}^{2}>50 \%$ [29]. A random effects model was used if the $I^{2}$ statistic was significant; otherwise, a fixed effects model was used. Pre-specified subgroup analyses based on follow-up duration ( $\geq 12$ months vs. $<12$ months), because studies suggested that the hair loss rate would decrease along with longer follow-up times. In addition, we performed a subgroup analysis based on the two most common procedures (RYGB vs. $\mathrm{SG})$. Meta-analysis results are expressed using forest plots.

\section{Results}

\section{Literature Retrieval Results and Basic Characteristics}

Figure 1 shows the study selection flowchart. Through the literature search, we identified 719 citations. Using the EndNote X9 software for document management, we
Fig. 1 Flow diagram of study selection

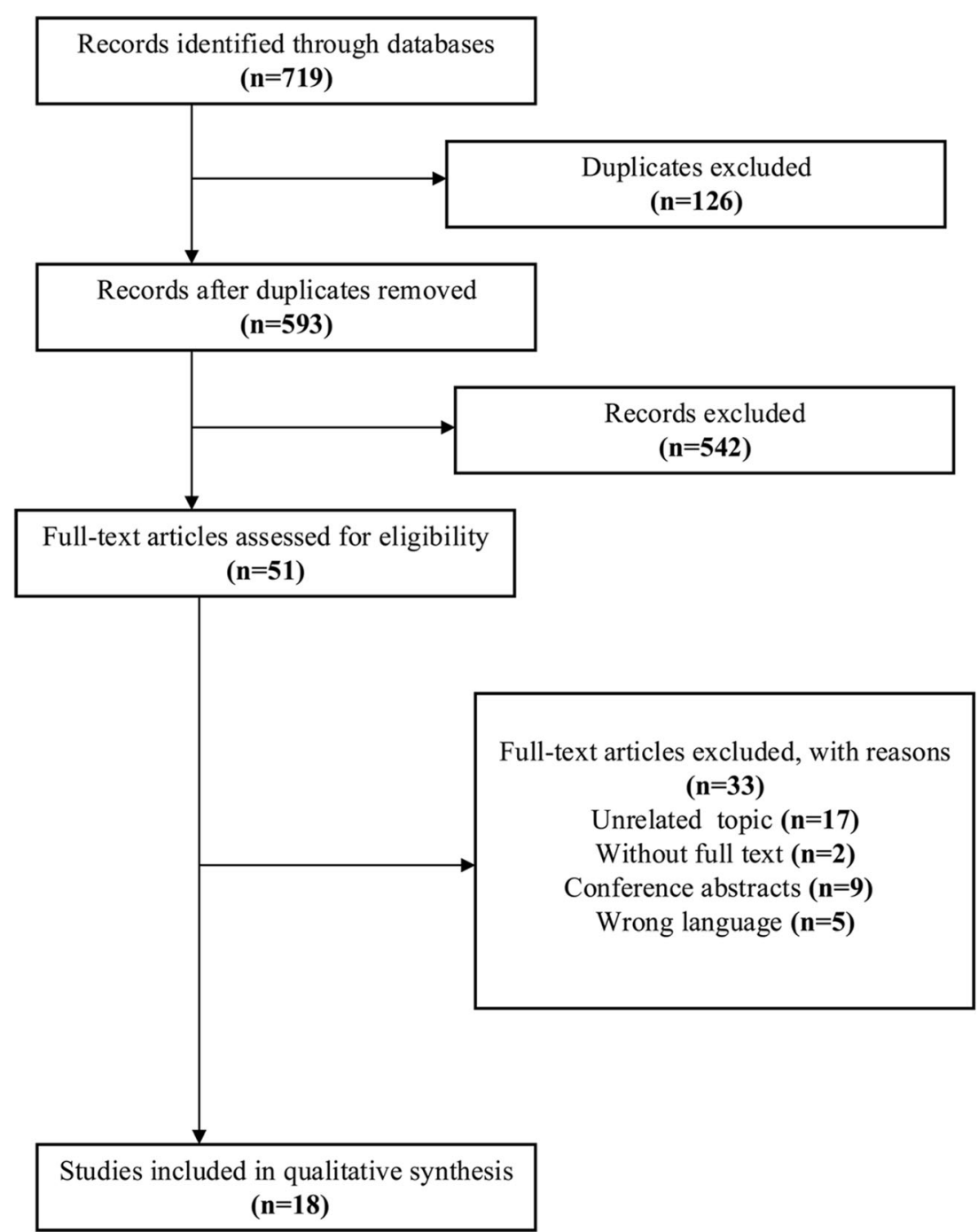


Fig. 2 Forest plots of overall incidence

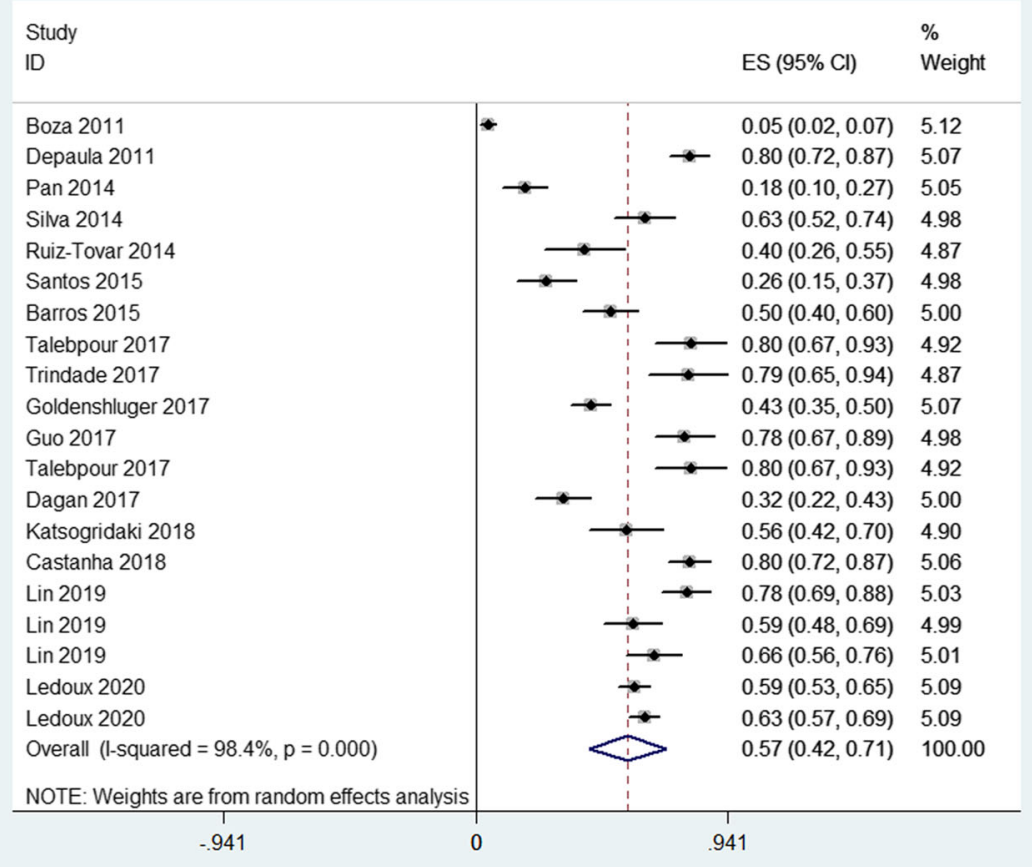

removed any duplicates and were left with 593 references. After excluding irrelevant reports by reviewing titles and abstracts, we then retrieved 51 full-text articles that were eligible. There were 17 articles with unrelated topics, 2 without full text, 9 conference abstracts, and 5 non-English/Chinese literatures excluded. Ultimately, 18 original articles were included, as shown in the study flowchart.

a

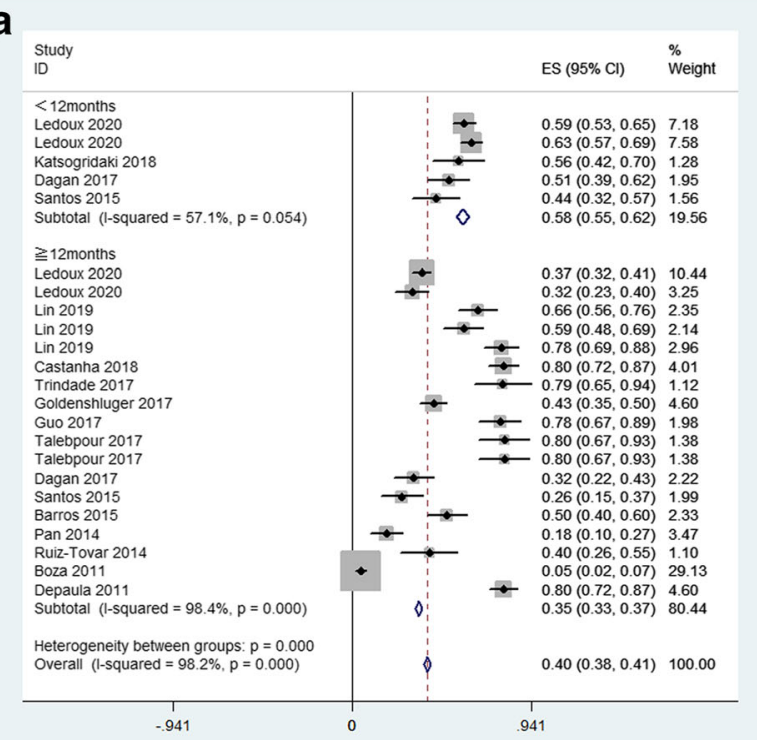

\section{Study Characteristics and Quality Assessment}

The study characteristics are presented in Table 1 . We identified 18 eligible studies $(N=2538)[4,5,8-10,13-25]$ that were published from 2011-2020. These studies included 1 RCT [8], 3 prospective observational studies [5, 10, 18], 8 retrospective observational studies $[4,9,13,15,17,19,20$, $25]$, and 5 cross-sectional studies [13, 14, 21-23]. The duration of follow-up ranges from 1 to 72 months. Four studies

b



Fig. 3 a Forest plots of follow-up duration. b Forest plots of procedures 


\begin{tabular}{|c|c|c|c|c|c|c|c|}
\hline \multirow[b]{2}{*}{ Study or Subgroup } & \multicolumn{3}{|c|}{ hair loss } & \multicolumn{3}{|c|}{ no hair loss } & \multirow[b]{2}{*}{ Weight } \\
\hline & Mean & SD & Total & Mean & SD & Total & \\
\hline Guo 2017 & 88 & 9 & 21 & 93 & 13 & 33 & $25.2 \%$ \\
\hline Katsogridaki 2018 & 0.46 & 0.13 & 28 & 0.73 & 0.13 & 22 & $24.4 \%$ \\
\hline Ledoux 2020 & 12.3 & 1.8 & 338 & 12.2 & 1.9 & 217 & $26.7 \%$ \\
\hline Ruiz-Tovar 2014 & 72.1 & 5.7 & 17 & 88.7 & 8 & 25 & $23.7 \%$ \\
\hline Total $(95 \% \mathrm{Cl})$ & & & 404 & & & 297 & $100.0 \%$ \\
\hline
\end{tabular}

Fig. 4 Forest plots of studies in serum zinc

analyzed the influencing factors of hair loss after MBS $[4,5,9$, 10]. Two studies were published in Chinese [9, 23]; the others were available in English.

According to the Newcastle-Ottawa Scale and AHRQ, the quality of observational studies was Low or moderate. The RCT, with a score of 5 on the Jadad scale, was a highquality study. The assessment of study quality is displayed in Table 1.

\section{Meta-analysis of Incidence of Hair Loss After MBS}

In this review, 18 articles $[4,5,8-10,13-25]$ including a total of 2538 patients were included. The overall incidence of hair loss ranged from $4.5 \%$ to $80 \%$. Because of significant heterogeneity among these studies ( $p=0.000, I^{2}=98.4 \%$ ) (Fig. 2$)$, a random effects model was used to pool the results. The results showed that the pooled incidence of hair loss was $57 \%$ (95\%CI, 42-71\%). The Egger $(p=0.005)$ test showed that there was significant publication bias in the literature. This may be due to the low quality of the included studies.

\section{Subgroup Analysis}

We performed subgroup analyses by follow-up duration $(\geq 12$ months vs. $<12$ months). When we looked at the subgroup

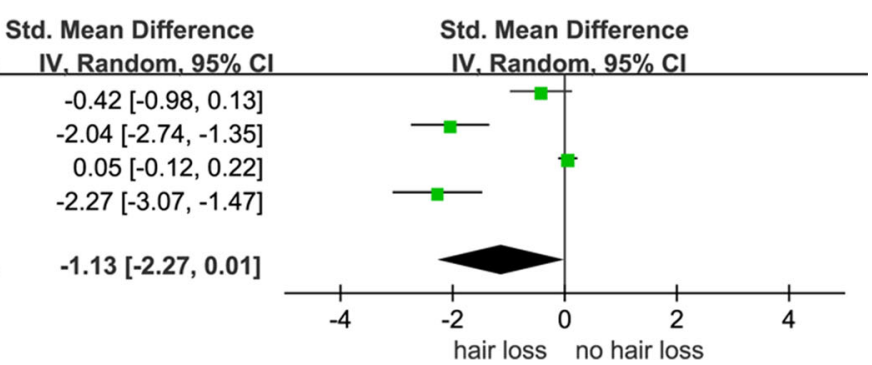

based on follow-up duration, a significant pooled result $(35 \%$, $95 \%$ CI 33 to $37 \%, p<0.1)$ was observed for the articles with long-term follow-up (LT $\geq 12$ months), but not for the studies with short-term follow-up (ST < 12 months) $(58 \%, 95 \%$ CI 55 to $62 \%, p=0.054)$. We found that the incidence of hair loss decreased with longer follow-up times, which decreased from58 (ST) to $35 \%$ (LT) (Fig. 3a).

In addition, we conducted a subgroup analysis based on the two most common procedures (SG vs RYGB) included in the study. When we looked at the subgroup of procedures, both the two subgroups had significant pooled results, but the incidence of hair loss was similar in both groups, with SG surgery $\left(51 \%, 95 \%\right.$ CI 48 to $\left.54 \%, p<0.1, I^{2}=94.2 \%\right)$ and RYGB surgery $\left(59 \%, 95 \%\right.$ CI 55 to $\left.63 \%, p<0.1, I^{2}=92.0 \%\right)($ Fig. 3b).

\section{Meta-analysis of Factors Influencing Hair Loss After MBS}

Five studies analyzed the factors related to hair loss after MBS $[4,5,9,10,23]$. A total of 783 patients were included, including 419 hair loss patients and 364 controls. Because the number of included studies was less than 10, publication bias was not checked for this outcome. We did not perform subgroup analyses.
Table 2 Studies of zinc and hair loss

\begin{tabular}{|c|c|c|}
\hline Author (year) & $\begin{array}{l}\text { Demographics } \\
\text { (hair loss group) }\end{array}$ & Measures and outcomes \\
\hline Ledoux 2020 [4] & $\begin{array}{l}\text { Sex: } 10 \mathrm{M} / 328 \mathrm{~F} \\
\text { Age: } 41.5 \pm 10.2 \\
\text { Country: France }\end{array}$ & $\begin{array}{l}\text { No difference in serum zinc levels in hair loss patients } \\
(12.3 \pm 1.8 \mu \mathrm{mol} / \mathrm{l}) \mathrm{vs} \text {. controls }(12.2 \pm 1.9 \mu \mathrm{mol} / \mathrm{l})\end{array}$ \\
\hline $\begin{array}{r}\text { Katsogridaki } \\
2018[10]\end{array}$ & $\begin{array}{l}\text { Sex: } 5 \mathrm{M} / 23 \mathrm{~F} \\
\text { Age: } 38.54 \pm 11.04 \\
\text { Country: Greece }\end{array}$ & $\begin{array}{l}\text { Mean zinc levels in hair loss patients }(0.46 \pm 0.13 \mathrm{mcg} / \mathrm{ml}) \\
\text { vs controls }(0.73 \pm 0.13 \mathrm{mcg} / \mathrm{ml})(p<0.01)\end{array}$ \\
\hline Guo 2017 [9] & $\begin{array}{l}\text { Sex: } 1 \mathrm{M} / 20 \mathrm{~F} \\
\text { Age: } 31 \pm 6 \\
\text { Country: China }\end{array}$ & $\begin{array}{l}\text { No difference in serum zinc levels in hair loss patients } \\
\quad(88 \pm 9 \mu \mathrm{mol} / \mathrm{l}) \text { vs. controls }(93 \pm 13 \mu \mathrm{mol} / \mathrm{l})\end{array}$ \\
\hline Ruiz-Tovar 2014 [5] & $\begin{array}{l}\text { Sex: } 0 \mathrm{~F} / 16 \mathrm{~F} \\
\text { Country: Spain }\end{array}$ & $\begin{array}{l}\text { Mean zinc levels in hair loss patients }(72.1 \pm 5.7 \mathrm{mg} / \mathrm{dL}) \\
\quad \text { vs controls }(88.7 \pm 8 \mathrm{mg} / \mathrm{dL})(p=0.021)\end{array}$ \\
\hline
\end{tabular}






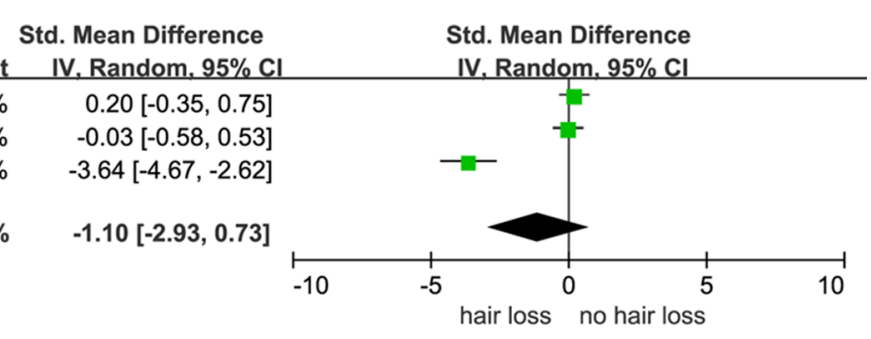

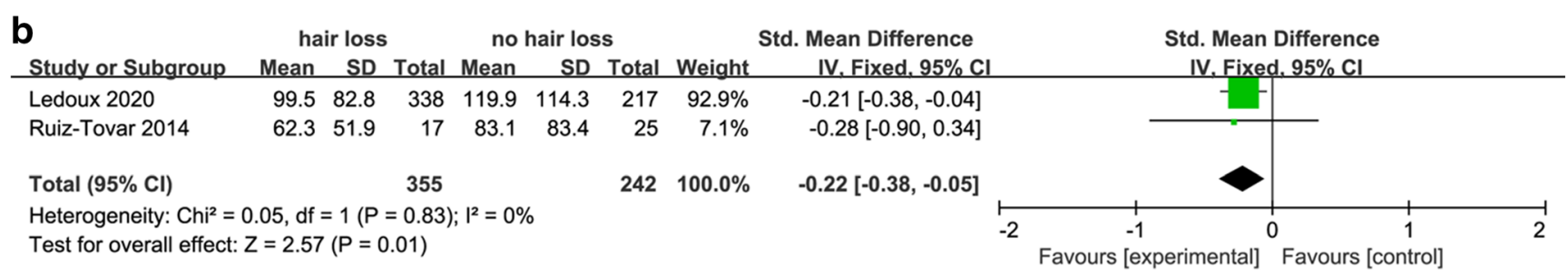

Fig. 5 a Forest plots of studies in serum iron. b Forest plots of studies in serum ferritin

\section{Zinc}

Four studies were included in the meta-analysis of zinc [4, 5, $9,10]$, with 701 patients overall (Table 2). Because of heterogeneity in included studies ( $p=0.05, I^{2}=95 \%$ ) (Fig. 4), a random effects model was chosen to pool results. It showed that zinc concentration was lower in patients with hair loss after MBS (SMD, $-1.13 ; 95 \% \mathrm{CI},-2.27$ to $0.01, p=0.05$ ) with the follow-up time was 6.8 months to 15 months.

\section{Iron and Ferritin}

For iron, a total of four studies were reviewed (Table 3). Three studies $[5,9,10]$ analyzed serum iron levels. Analysis of extracted data showed that there were no significant differences in serum iron levels between patients with or without hair loss after MBS (SMD, $-1.10 ; 95 \% \mathrm{CI},-2.93$ to $0.73 ; p=0.24$ ). The heterogeneity was high $I^{2}=96 \%$ (Fig. 5a), random effect model was used.
Two studies $[4,5]$ analyzed serum ferritin levels, and both showed lower levels in patients reporting hair loss after MBS (SMD, $-0.22 ; 95 \%$ CI, -0.38 to $-0.05 ; p=0.01$ ). Significant heterogeneity was not found $I^{2}=0 \%$ (Fig. 5 b), so a fixed effects model was used.

\section{Folic Acid and Vitamin $\mathbf{B}_{12}$}

Studies about the role of folic acid and vitamin $\mathrm{B}_{12}$ in hair loss after MBS are summarized in (Table 4). Two of the studies reported the outcome of folic acid levels. Because of heterogeneity among these studies $\left(p<0.0001, I^{2}=48 \%\right)$, a fixed effects model was used to pool results. The result showed that folic acid levels were lower in patients with hair loss (SMD, $0.88,95 \%$ CI -1.29 to $-0.46, p<0.0001$ ) (Fig. 6a). The overall analysis showed lower vitamin $\mathrm{B}_{12}$ levels in patients reporting hair loss $(\mathrm{SMD},-0.40 ; 95 \% \mathrm{CI},-1.59$ to $0.79 ; p=$ 0.51 ) (Fig. 6b). The heterogeneity was high $I^{2}=88 \%$, a random effects model was used to pool results.

Table 3 Studies of iron and ferritin and hair loss

\begin{tabular}{|c|c|c|}
\hline Author (year) & Demographics (hair loss group) & Measures and outcomes \\
\hline Ledoux $2020[4]$ & $\begin{array}{l}\text { Sex: } 10 \mathrm{M} / 328 \mathrm{~F} \\
\text { Age: } 41.5 \pm 10.2 \\
\text { Country: France }\end{array}$ & $\begin{array}{l}\text { Mean ferritin levels in hair loss patients }(99.5 \pm 82.8 \mu \mathrm{g} / \mathrm{l}) \mathrm{vs} \text { controls } \\
\quad(119.9 \pm 114.3 \mu \mathrm{g} / \mathrm{l})(p<0.05)\end{array}$ \\
\hline Katsogridaki 2018 [10] & $\begin{array}{l}\text { Sex: } 5 \mathrm{M} / 23 \mathrm{~F} \\
\text { Age: } 38.54 \pm 11.04 \\
\text { Country: Greece }\end{array}$ & $\begin{array}{l}\text { No difference in serum iron levels in hair loss patients }(63.36 \pm 22.31) \mathrm{vs} \text {. } \\
\text { controls }(63.91 \pm 20.65)(p>0.05)\end{array}$ \\
\hline Guo 2017 [9] & $\begin{array}{l}\text { Sex: } 1 \mathrm{M} / 20 \mathrm{~F} \\
\text { Age: } 31 \pm 6 \\
\text { Country: China }\end{array}$ & $\begin{array}{l}\text { No difference in serum iron levels in hair loss patients }(8.7 \pm 0.5 \mathrm{mmol} / \mathrm{l}) \mathrm{vs} \text {. } \\
\text { controls }(8.6 \pm 0.5 \mathrm{mmol} / \mathrm{l})(p>0.05)\end{array}$ \\
\hline Ruiz-Tovar 2014 [5] & $\begin{array}{l}\text { Sex: } 0 \mathrm{~F} / 16 \mathrm{~F} \\
\text { Country: Spain }\end{array}$ & $\begin{array}{l}\text { Mean iron levels in hair loss patients }(42.2 \pm 5.7 \mathrm{mg} / \mathrm{dL}) \text { vs controls } \\
(91.8 \pm 16.6 \mathrm{mg} / \mathrm{dL})(p=0.017) \\
\text { Mean ferritin levels in hair loss patients }(62.3 \pm 51.9 \mathrm{ng} / \mathrm{mL}) \text { vs. controls } \\
(83.1 \pm 83.4 \mathrm{ng} / \mathrm{mL})(p>0.05)\end{array}$ \\
\hline
\end{tabular}




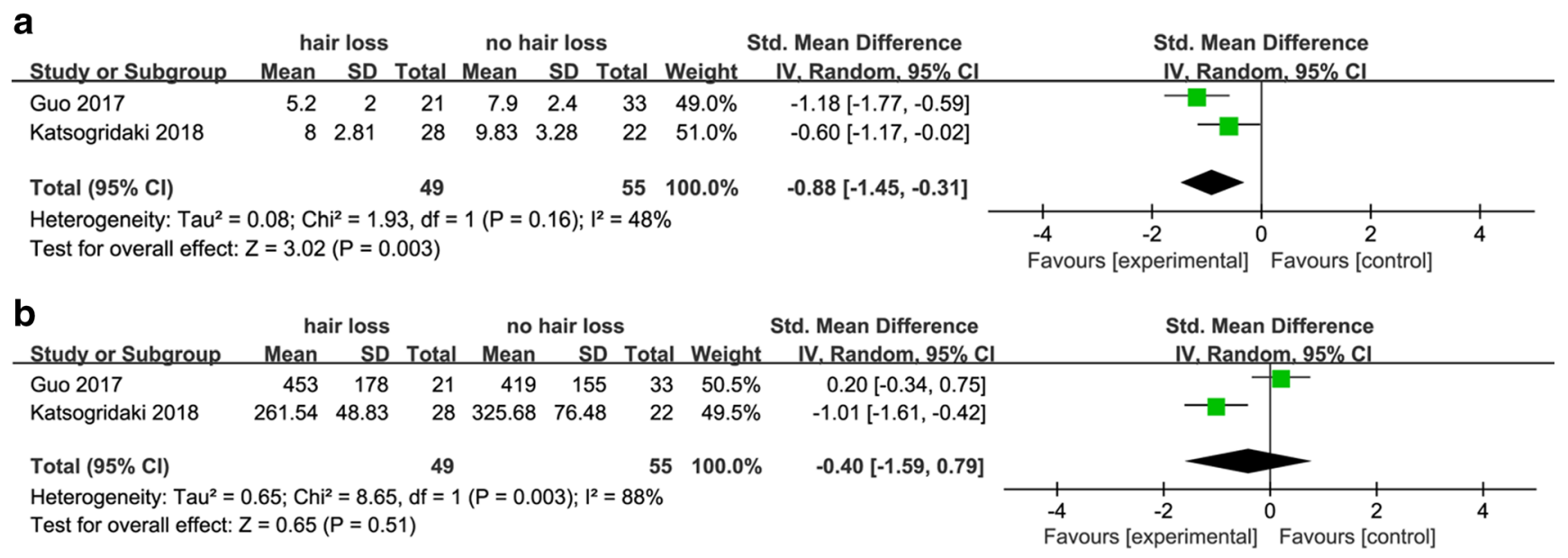

Fig. 6 a Forest plots of studies in folic acid. b Forest plots of studies in vitamin $B_{12}$

\section{Gender and Age}

Studies of gender and age in hair loss after MBS are summarized in (Table 5). Hair loss after MBS was more common in women (OR, $3.87 ; 95 \% \mathrm{CI}, 0.59$ to $17.59 ; p=0.08 ; I^{2}=85 \%$ ) (Fig. 7a), and patients with hair loss were younger than controls (MD, $-2.45 ; 95 \% \mathrm{CI},-4.26$ to $-0.64 ; p=0.008 ; I^{2}=0$ )

(Fig. 7b).

\section{Discussion}

Hair loss is common after MBS, but there is considerable debate in the scientific literature about its overall incidence and etiopathogenesis. This is the first systematic review in scientific literature on this topic. We found that hair loss happens in $57 \%$ of patients after MBS and that its incidence decreases with longer follow-up times. Serum zinc, ferritin and folic acid levels seem to be lower in patients with hair loss compared with controls. Moreover, young women are more likely to have hair loss. In contrast, evidence remains inconclusive to support any association with low iron or vita$\min \mathrm{B}_{12}$ levels.
In this review, there were 18 studies with data regarding hair loss incidence $[4,5,8-10,13-25]$. From the data, the overall incidence was $57 \%$. The incidence decreased from $58 \%$ at less than 12 months follow-up to $35 \%$ with more than or equal to 12 months follow-up. This is similar to findings by Guo et al. [9] who observed that hair loss stopped, and new hair gradually grew in all patients after LSG during the followup. A retrospective study conducted by Ledoux et al. [4] found that the incidence of hair loss decreases from $65 \%$ at $<12$ months to $35 \%$ at $>12$ months follow-up. Most of the weight loss after MBS happens in the first year after surgery [30]. It is possible that the loss of subcutaneous tissue makes it difficult for the scalp to support hair [9].

There were few comparative studies on hair loss after different types of surgeries. Although our results showed that the incidence of hair loss after SG and RYGB was similar, we should treat this result with caution.

We also found that hair loss after MBS was more common in women and patients with hair loss were younger than controls. Researchers have proposed that women have longer hair than men and have higher requirements for scalp support [9]. Moreover, younger women may report hair loss more frequently, from an esthetic perspective [4]. This might indicate a special need for attention in younger women after surgery.

Table 4 Studies of folic acid and vitaminB $\mathrm{B}_{12}$ and hair loss

\begin{tabular}{|c|c|c|}
\hline Author (year) & $\begin{array}{l}\text { Demographics } \\
\text { (hair loss group) }\end{array}$ & Measures and outcomes \\
\hline $\begin{array}{c}\text { Katsogridaki } \\
2018 \text { [10] }\end{array}$ & $\begin{array}{l}\text { Sex: } 5 \mathrm{M} / 23 \mathrm{~F} \\
\text { Age: } 38.54 \pm 11.04 \\
\text { Country: Greece }\end{array}$ & $\begin{array}{l}\text { Mean folic acid levels: hair loss }(8 \pm 2.81 \mathrm{ng} / \mathrm{ml}) \text { vs. controls }(9.83 \pm 3.28 \mathrm{ng} / \mathrm{ml})(p=0.039) \\
\text { vitamin } B_{12} \text { : hair loss }(261.54 \pm 48.83 \mathrm{pg} / \mathrm{ml}) \text { vs. controls }(325.68 \pm 76.48 \mathrm{pg} / \mathrm{ml})(p=0.001)\end{array}$ \\
\hline Guo 2017 [9] & $\begin{array}{l}\text { Sex: } 11 \mathrm{M} / 43 \mathrm{~F} \\
\text { Age: } 31 \\
\text { Country: China }\end{array}$ & $\begin{array}{l}\text { No difference in vitamin } \mathrm{B}_{12} \text { levels in hair loss patients }(453 \pm 178 \mathrm{ng} / \mathrm{L}) \text { vs. controls } \\
\quad(419 \pm 155 \mathrm{ng} / \mathrm{L})(p>0.05) \\
\text { Mean folic acid levels in hair loss patients }(5.2 \pm 2.0 \mu \mathrm{g} / \mathrm{L}) \text { vs. controls }(7.9 \pm 2.4 \mu \mathrm{g} / \mathrm{L}) \\
(p<0.05)\end{array}$ \\
\hline
\end{tabular}


a

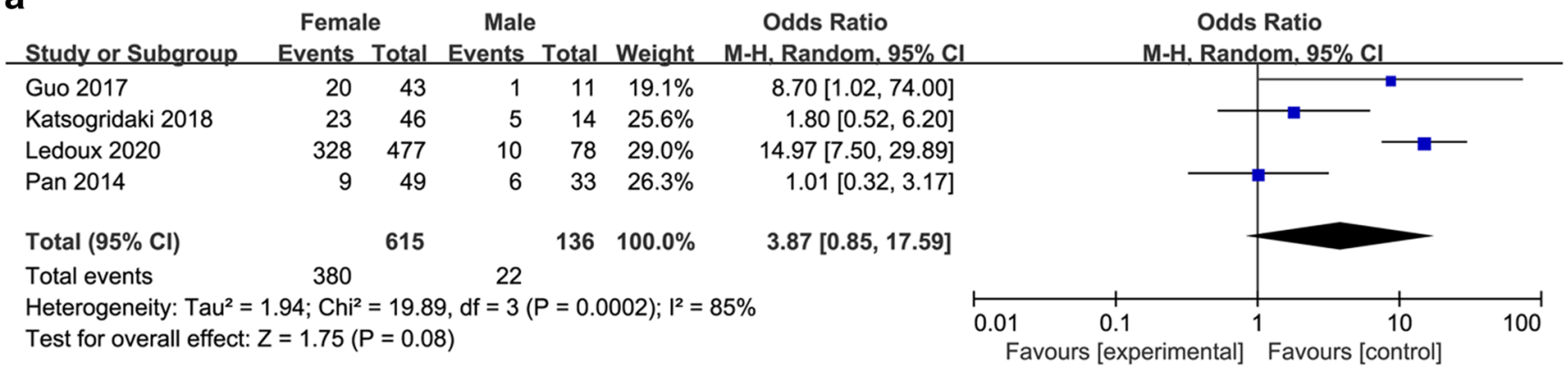

b

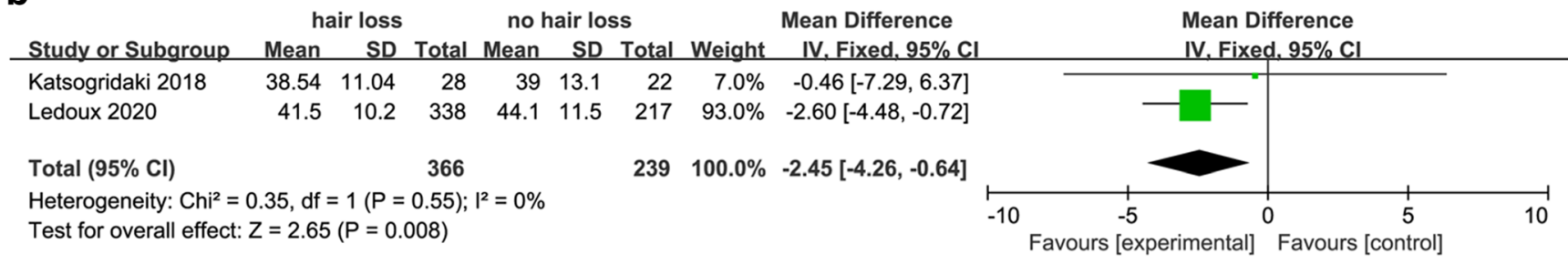

Fig. 7 a Forest plots of studies in gender. b Forest plots of studies in age

Our meta-analysis found zinc deficiency to be associated with hair loss after MBS $(p=0.05)$ which is consistent with other reviews and meta-analyses showing an association between alopecia and zinc levels [31-33]. Though it may not be cost-effective to screen for and treat all zinc deficiency after MBS, one should ensure that patients, particularly those undergoing a gastric bypass are on multivitamin tablets that provide at least $30 \mathrm{mg}$ of zinc daily [34]. Patients with significant hair loss may benefit from higher dosages of zinc supplementation.

Iron deficiency is a common occurrence after MBS but its relationship with hair loss after MBS is controversial [35-41]. In this review, serum ferritin levels were significantly associated with hair loss following MBS, but serum iron levels were not. Serum ferritin levels reflect a patient's total iron storage [42]. However, studies have shown that serum ferritin levels may be altered with infectious, inflammatory, and neoplastic conditions [42]. That is why we have concluded that there is currently insufficient evidence to claim a role for iron deficiency as a causative factor for hair loss after MBS.

There is a paucity of data on folic acid and vitamin $B_{12}$ levels in patients with and without hair loss following MBS in the published literature. Only two studies presented data on folic acid and vitamin $B_{12}$ levels $[9,10]$. Results suggested that there were significant differences in folic acid levels between both groups. Further analysis showed that vitamin $\mathrm{B}_{12}$ was not associated with hair loss. Because of the low number of eligible studies, this finding has to be treated with caution and further studies are necessary before we can reach any conclusion.

In addition to the above, Ledoux et al. [4] found that, in subjects with hair loss, blood parameters of protein were significantly lower than in subjects without hair loss. Postoperative excess weight loss (EWL) was found to be a

Table 5 Studies of age and gender and hair loss

\begin{tabular}{lll}
\hline Author (Year) & Demographics (hair loss group) & Measures and outcomes \\
\hline Ledoux 2020 [4] & Sex: $10 \mathrm{M} / 328 \mathrm{~F}$ & Age (years): hair loss patients $(41.5 \pm 10.2)$ vs. controls $(44.1 \pm 11.5)(p<0.05)$ \\
& Age: $41.5 \pm 10.2$ & Gender: male $(10 / 78)$ vs. female with $(328 / 477)(p=0.02)$ \\
& Country: France & \\
Katsogridaki 2018 [10] & Sex: $5 \mathrm{M} / 23 \mathrm{~F}$ & Age: no difference between hair loss patients $(38.5 \pm 11.04$ years) and controls \\
& Age: $38.54 \pm 11.04$ & $(39 \pm 13.1$ years) $(p=0.892)$ \\
& Country: Greece & Gender: male $(5 / 14)$ vs. female $(23 / 36)(p=0.072)$ \\
Guo 2017 [9] & Sex: $11 \mathrm{M} / 43 \mathrm{~F}$ & Age: no difference between hair loss patients $(31 \pm 6$ years $)$ and controls \\
& Age: 31 & $(30 \pm 7$ years $)(p>0.05)$ \\
& Country: China & Gender: male $(1 / 11)$ vs. female $(20 / 43)(p=0.02)$ \\
Pan 2014 [23] & Sex: $6 \mathrm{M} / 9 \mathrm{~F}$ & NR \\
& Age: NR & \\
& Country: China & \\
\hline
\end{tabular}

$N R$ not reported 
significant factor in the study by Guo et al. [9] Moreover, acute stress, such as surgical trauma, catabolic state after bariatric surgery, and psychological stress due to factors such as stigma and discrimination associated with obesity and surgery [43], may inhibit hair growth through the release of cortisol and substance P-mast cell pathway. The stress hormone cortisol reduces synthesis and speeds up the degradation of important skin components [44]. All these factors can also be hypothesized to play a role in the etio-pathogenesis of hair loss after MBS.

\section{Strengths and Limitations}

To our knowledge, this is the first systematic review and metaanalysis on hair loss after bariatric surgery.

Our review has some limitations. Firstly, the number of included studies on the effects of hair loss is limited, which may affect the reliability of the results. More studies are needed on this topic. Moreover, reporting of hair loss by patients can be very subjective. There is currently a lack of standardized criteria for the diagnosis of this condition.

Lastly, most of the included studies were retrospective observational studies, which means our findings need further confirmation in higher quality studies. Randomized studies are needed.

\section{Conclusions}

Approximately $57.0 \%$ of patients experience hair loss after metabolic and bariatric surgery. Younger age, female sex, low folic acid levels, low zinc levels, and low ferritin levels were associated with it. Our findings could prove helpful in the diagnosis and treatment of these patients. Larger, randomized studies are needed.

\section{Declarations}

Ethics Approval For this type of study, formal consent is not required.

Consent to Participate Informed consent does not apply.

Conflict of Interest The authors declare no competing interests.

Open Access This article is licensed under a Creative Commons Attribution 4.0 International License, which permits use, sharing, adaptation, distribution and reproduction in any medium or format, as long as you give appropriate credit to the original author(s) and the source, provide a link to the Creative Commons licence, and indicate if changes were made. The images or other third party material in this article are included in the article's Creative Commons licence, unless indicated otherwise in a credit line to the material. If material is not included in the article's Creative Commons licence and your intended use is not permitted by statutory regulation or exceeds the permitted use, you will need to obtain permission directly from the copyright holder. To view a copy of this licence, visit http://creativecommons.org/licenses/by/4.0/.

\section{References}

1. Chooi YC, Ding C, Magkos F. The epidemiology of obesity. Metabolism. 2019;92:6-10.

2. National Clinical Guideline C. National Institute for Health and Clinical Excellence: Guidance. Obesity: identification, assessment and management of overweight and obesity in children, young people and adults: partial update of CG43. London: National Institute for Health and Care Excellence (UK) 2014.

3. Singhal R, Tahrani AA, Ludwig C, et al. Global 30-day outcomes after bariatric surgery during the COVID-19 pandemic (GENEVA): an international cohort study. Lancet Diabetes Endocrinol. 2021;9:7-9.

4. Ledoux S, Flamant M, Calabrese D, et al. What are the micronutrient deficiencies responsible for the most common nutritional symptoms after bariatric surgery? Obes Surg. 2020;30:1891-7.

5. Ruiz-Tovar J, Oller I, Llavero C, et al. Hair loss in females after sleeve gastrectomy: predictive value of serum zinc and iron levels. Am Surg. 2014;80:466-71.

6. Schielein MC, Tizek L, Ziehfreund S, et al. Stigmatization caused by hair loss - a systematic literature review. J Dtsch Dermatol Ges. 2020;18:1357-68.

7. Wang C, Yang W, Yang J. Surgical results of laparoscopic Rouxen-Y gastric bypass in super obese patients with $B M I \geq 60$ in China. Surg Laparosc Endosc Percutan Tech. 2014;24:e216-20.

8. Talebpour M, Sadid D, Talebpour A, et al. Comparison of shortterm effectiveness and postoperative complications: laparoscopic gastric plication vs laparoscopic sleeve gastrectomy. Obes Surg. 2018;28:996-1001.

9. Guo H, Zhu J, Ma Y, et al. Risk factors analysis of hair loss in obese patients after laparoscopic sleeve gastrectomy. Chin J Dig Dis Surg. 2017;16:592-5.

10. Katsogridaki G, Tzovaras G, Sioka E, et al. Hair loss after laparoscopic sleeve gastrectomy. Obes Surg. 2018;28:3929-34.

11. Sen O, Turkcapar AG. Hair Loss after sleeve gastrectomy and effect of biotin supplements. J Laparoendosc Adv Surg Tech A. 2020;

12. Moher D, Liberati A, Tetzlaff J, et al. Preferred reporting items for systematic reviews and meta-analyses: the PRISMA statement. Int J Surg. 2010;8:336-41.

13. Lin S, Guan W, Yang N, et al. Short-term outcomes of sleeve gastrectomy plus jejunojejunal bypass: a retrospective comparative study with sleeve gastrectomy and Roux-en-Y gastric bypass in Chinese patients with BMI $\geq 35 \mathrm{~kg} / \mathrm{m} 2$. Obes Surg. 2019;29: 1352-9.

14. Castanha CR, Tcbc-Pe AABF, Castanha AR, et al. Evaluation of quality of life, weight loss and comorbidities of patients undergoing bariatric surgery. Rev Col Bras Cir. 2018;45:e1864-e.

15. Du X, Fu XH, Peng BQ, et al. Resolution of metabolic syndrome and related metabolic disorders after bariatric surgery: comparison of sleeve gastrectomy and gastric bypass. Surg Obes Relat Dis. 2018; 14:1348-56.

16. Trindade EM, Gebara TSES, Cambi MPC, et al. Nutritional aspects and the use of nutritional supplements by women who underwent gastric bypass. Arq Bras Cir Dig. 2017;30:11-3.

17. Goldenshluger M, Goldenshluger A, Keinan-Boker L, et al. Postoperative outcomes, weight loss predictors, and late gastrointestinal symptoms following laparoscopic sleeve gastrectomy. J Gastrointest Surg. 2017;21:2009-15. 
18. Sherf Dagan S, Keidar A, Raziel A, et al. Do bariatric patients follow dietary and lifestyle recommendations during the first postoperative year? Obes Surg. 2017;27:2258-71.

19. Lee SK, Heo Y, Park JM, et al. Roux-en-Y gastric bypass vs. sleeve gastrectomy vs. gastric banding: The first multicenter retrospective comparative cohort study in obese Korean patients. Yonsei Med J. 2016;57:956-62.

20. dos Santos TD, Burgos MG. de Lemos Md.a C, Cabral PC. Clinical and nutritional aspects in obese women during the first year after Roux-en-Y gastric bypass. Arq Bras Cir Dig. 2015;28:56-60.

21. Barros LM, Frota NM, Moreira RA, et al. Assessment of bariatric surgery results. Rev Gaucha Enferm. 2015;36:21-7.

22. da Silva PR, de Souza MR, da Silva EM, et al. Nutritional status and life quality in patients undergoing bariatric surgery. Arq Bras Cir Dig. 2014;27(Suppl 1):35-8.

23. Pan Y, Tan J, Nong Y, Chen W, Li H, Zhuo G. Nutritional care and guidelines for patients undergoing laparoscopic sleeve gastrectomy. Nurs J Chin PLA. 2014;31:43-6.

24. Boza C, Gamboa C, Perez G, et al. Laparoscopic adjustable gastric banding (LAGB): surgical results and 5-year follow-up. Surg Endosc. 2011;25:292-7.

25. Depaula AL, Stival AR, Halpern A, et al. Surgical treatment of morbid obesity: Mid-term outcomes of the laparoscopic ileal interposition associated to a sleeve gastrectomy in 120 patients. Obes Surg. 2011;21:668-75.

26. Stang A. Critical evaluation of the Newcastle-Ottawa scale for the assessment of the quality of nonrandomized studies in meta-analyses. Eur J Epidemiol. 2010;25:603-5.

27. Rostom A, Dubé C, Cranney A, et al. Celiac disease. Rockville (MD): agency for healthcare research and quality (US); 2004 Sep.(evidence Reports/Technology assessments, no. 104.) appendix D. quality assessment forms. 2014

28. Jadad AR, Moore RA, Carroll D, et al. Assessing the quality of reports of randomized clinical trials: is blinding necessary? Control Clin Trials. 1996;17:1-12.

29. Chen B, Benedetti A. Quantifying heterogeneity in individual participant data meta-analysis with binary outcomes. Syst Rev. 2017;6: 243.

30. Takemoto E, Wolfe BM, Nagel CL, et al. Insurance status differences in weight loss and regain over 5 years following bariatric surgery. Int J Obes. 2018;42:1211-20.

31. Jin W, Zheng H, Shan B, et al. Changes of serum trace elements level in patients with alopecia areata: A meta-analysis. J Dermatol. 2017:44:588-91.
32. Thompson JM, Mirza MA, Park MK, et al. The Role of Micronutrients in Alopecia Areata: A Review. Am J Clin Dermatol. 2017;18:663-79.

33. Almohanna HM, Ahmed AA, Tsatalis JP, et al. The role of vitamins and minerals in hair loss: a review. Dermatol Ther (Heidelb). 2019;9:51-70.

34. Mahawar KK, Bhasker AG, Bindal V, et al. Zinc Deficiency after gastric bypass for morbid obesity: a systematic review. Obes Surg. 2017;27:522-9.

35. Benotti PN, Wood GC, Still CD, et al. Metabolic surgery and iron homeostasis. Obes Rev. 2019;20:612-20.

36. Dogan K, Homan J, Aarts EO, et al. Long-term nutritional status in patients following Roux-en-Y gastric bypass surgery. Clin Nutr. 2018;37:612-7.

37. Al-Mutawa A, Al-Sabah S, Anderson AK, et al. Evaluation of Nutritional status post laparoscopic sleeve gastrectomy-5-year outcomes. Obes Surg. 2018;28:1473-83.

38. Caron M, Hould FS, Lescelleur O, et al. Long-term nutritional impact of sleeve gastrectomy. Surg Obes Relat Dis. 2017;13: 1664-73.

39. Ledoux S, Calabrese D, Bogard C, et al. Long-term evolution of nutritional deficiencies after gastric bypass: an assessment according to compliance to medical care. Ann Surg. 2014;259:1104-10.

40. Coupaye $\mathrm{M}$, Rivière $\mathrm{P}$, Breuil $\mathrm{MC}$, et al. Comparison of nutritional status during the first year after sleeve gastrectomy and Roux-en-Y gastric bypass. Obes Surg. 2014;24:276-83.

41. Coupaye M, Puchaux K, Bogard C, et al. Nutritional consequences of adjustable gastric banding and gastric bypass: a 1-year prospective study. Obes Surg. 2009;19:56-65.

42. Trost LB, Bergfeld WF, Calogeras E. The diagnosis and treatment of iron deficiency and its potential relationship to hair loss. J Am Acad Dermatol. 2006;54:824-44.

43. Phelan SM. An update on research examining the implications of stigma for access to and utilization of bariatric surgery. Curr Opin Endocrinol Diabetes Obes. 2018;25:321-5.

44. Staufenbiel SM, Penninx BW, Spijker AT, et al. Hair cortisol, stress exposure, and mental health in humans: a systematic review. Psychoneuroendocrinology. 2013;38:1220-35.

Publisher's Note Springer Nature remains neutral with regard to jurisdictional claims in published maps and institutional affiliations. 